\title{
The Effects of a Dynamic Tuberal Support on Ischial Buttock Load and Pattern of Blood Supply
}

\author{
Paul van Geffen, Jasper Reenalda, Peter H. Veltink, Senior Member, IEEE, and Bart F. J. M. Koopman
}

\begin{abstract}
Sitting acquired pressure ulcers are places of tissue breakdown that mainly occur under the ischial tuberosities (ITs). Successive durations of pressure relief help the buttock tissue recover from sustained deformation and blood-flow stagnation. A computer-aided simulator chair was developed with two adjustable tuberal support elements (TSE) integrated in a force-sensing seating plane (FSP). This study investigated the redistribution of external buttock load in relation to the pattern (i.e., dynamics) of subtuberal blood supply in sitting with a dynamic tuberal support of $1 / 60 \mathrm{~Hz}(80 \mathrm{~mm} / \mathrm{min})$. Fifteen healthy male subjects were seated with their ITs on the TSE. The experiment involved periodic TSE adjustment in which buttock interface pressure was measured with the FSP and an external pressure mapping device (PMD). Light-guide tissue spectrophotometry was used for simultaneous noninvasive measurement of oxygenation and perfusion in the skin $(<2 \mathrm{~mm})$ and subcutaneous $(<8 \mathrm{~mm})$ tissue under the ITs. TSE adjustment seemed effective to regulate centre of buttock pressure and the forces under the ITs. Differences in measurement with the FSP and PMD have been found due to Hammocking at the seat interface and inaccurate peak pressure readings. Subtuberal blood supply was inversely related to the contact load under the ITs. A rapid inflow of blood in the initial stage of tuberal unloading, followed by a gradual outflow in the rest of the movement cycle indicates that the average blood supply increases when the adjustment frequency increases. Future studies must address the influence of a dynamic tuberal support on the ischial buttock load and pattern of blood supply in impaired individuals.
\end{abstract}

Index Terms-Blood supply, buttock load, pressure ulcer, seating.

\section{NOMENCLATURE}

FSP Force sensing seating plane.

ITs Ischial tuberosities.

O2C Oxygen-to-see.

PMD Pressure mapping device.

TSE Tuberal support elements.

Manuscript received September 25, 2008; revised October 02, 2009; accepted October 26, 2009. First published January 12, 2010; current version published February 24, 2010. This work was supported by the Dutch Ministry of Economical Affairs, SenterNovem under Grant TSIT3043.

P. van Geffen and B. F. J. M. Koopman are with the Institute for Biomedical Technology (Mira), Laboratory of Biomechanical Engineering, Department of Engineering Technology, University of Twente, 7500 AE Enschede, The Netherlands (e-mail: h.f.j.m.koopman@utwente.nl).

J. Reenalda is with Roessingh Research and Development, 7500 AH Enschede, The Netherlands (e-mail j.reenalda@ $@$ rd.nl).

P. H. Veltink is with the University of Twente, 7500 AE Enschede, The Netherlands (e-mail p.h.veltink@utwente.nl).

Color versions of one or more of the figures in this paper are available online at http://ieeexplore.ieee.org.

Digital Object Identifier 10.1109/TNSRE.2009.2039384

\author{
D Tuberal adjustment. \\ $\mathrm{DI}_{\mathrm{f}} \quad$ Dispersion index measured with the force sensing \\ seating plane (FSP). \\ $\mathrm{DI}_{\mathrm{p}} \quad$ Dispersion index measured with the external \\ pressure mapping device (PMD). \\ $\mathrm{CP}_{\mathrm{f}} \quad$ Centre of pressure measured with FSP. \\ $\mathrm{CP}_{\mathrm{p}} \quad$ Centre of pressure measured with PMD. \\ $\mathrm{SO} 2_{\text {sk }} \quad$ Skin buttock tissue oxygenation. \\ $\mathrm{F}_{\mathrm{sk}} \quad$ Skin buttock tissue perfusion. \\ $\mathrm{SO} 2_{\mathrm{sc}}$ Subcutaneous buttock tissue oxygenation. \\ $\mathrm{F}_{\mathrm{sc}} \quad$ Subcutaneous buttock tissue perfusion.
}

\section{INTRODUCTION}

$\mathbf{W}$ HEELCHAIR-USERS who cannot reposition themselves often suffer from pressure ulcers, which are localized places of tissue breakdown that mainly occur in the buttock tissue under the ischial tuberosities (ITs) [1], [2]. Current research findings discriminate between superficial and deep pressure ulcers [1], [3]. Superficial pressure ulcers occur in the skin from sustained shear and pressure on the buttock interface, and deep pressure ulcers occur from sustained internal buttock loading and are often located in the muscle tissue directly under bony structures. This latter type of injury is extremely hard to treat because it progresses outwards to the skin and when it manifests at the buttock surface it already caused severe damage to the subdermal tissue.

There is evidence that deep tissue breakdown initiates subdermally, even when comparatively low pressures exert at the buttock surface [4]. Experimental research with muscle-cell cultures [5]-[8], finite element models [9]-[14], animals [15], [16], and humans [3], [17] have been preformed to reveal the exact cause, onset, location and extent of deep tissue damage from sustained internal loading. Recent studies of Stekelenburg et al. demonstrated that the onset of deep pressure ulcers involves a complex interplay of prolonged ischemia together with excessive friction and shear loading due to high internal pressure gradients [18], [19]. Although the exact cause remains unclear, it has been recognized that successive durations of pressure relief help buttock tissue recover from sustained deformation and blood flow stagnation.

Common applications to prevent pressure ulcers are based on seating surfaces that distribute the buttock pressure over a larger area and locally reduce the applied pressure under the ITs [20]. The process of reshaping the seating surface for optimal 
pressure distribution often involves a protracted and iterative procedure. Some computer-aided seating systems [21]-[23], equipped with a matrix of adjustable force sensing support elements, have therefore been developed that automatically adjust the surface shape based on preprogrammed criteria for interface pressure and soft tissue characteristics. Although the effectiveness of designing individualized contour shaped seat surfaces have been demonstrated [24], systems like these are often too complex and expensive to be integrated as an assistive technology in daily wheelchair-use.

When static seating surfaces do not relieve buttock pressure enough, dynamic buttock supports appeared useful for proper pressure management [25]-[27]. We therefore developed a computer-aided simulator chair with two adjustable support elements under the ITs [28]. Built-in measurement of seat reaction forces allows quantitative assessment of the external buttock load during support surface manipulations.

However, it has been recognized that the external buttock pressure provides only little information about the internal mechanical and physiological tissue conditions [29]. Finite element studies showed that there is no distinct relation between the interface pressure and internal buttock load [9], [29]-[31]. It has been found that comparatively low pressures at the buttock interface could still lead to high internal stress levels under the bony prominences [4]. A potential threat for deep pressure ulcers remains, even when the buttock interface pressure is evenly distributed.

Levels of oxygenation and perfusion are important indicators for the viability of tissue and can be used for quantitative assessment of peripheral perfusion and microcirculation in skin and subcutaneous tissue [32]. Additional measurement of the ischial blood supply has therefore been suggested as being useful when quantifying the risk for pressure ulcers in vivo [2].

In a previous study [33], we investigated the effects of different alternating tuberal support strategies on skin and subcutaneous subtuberal tissue oxygenation and perfusion. Nine different support conditions of 5 min were successively imposed; four periods of static loading and unloading, followed by five periods of dynamic loading and unloading with various adjustment frequencies. We found that in sitting with static loaded tuberal support, the average blood supply was significantly lower compared to sitting with static unloaded tuberal support and dynamic tuberal support. Furthermore, a trend $(p>0.05)$ was observed that the average level of skin oxygenation and subcutaneous tissue perfusion increased when the frequency of adjustment increased. This could indicate that the metabolic process of blood outflow due to tissue loading was slower than the mechanical process of blood inflow due to tissue unloading. However, we only compared the average blood supply between support conditions, and the dynamics of blood supply has therefore not yet been analyzed.

The present study is complementary to this previous work. It investigates the redistribution of buttock load in combination with noninvasive measurement of subtuberal buttock tissue oxygenation and perfusion in sitting with a dynamic tuberal support of $1 / 60 \mathrm{~Hz}(80 \mathrm{~mm} / \mathrm{min})$, for which the pattern (i.e., dynamics) of blood supply in relation to the external buttock load is analyzed with a more in-depth focus.

\section{METHODS}

\section{A. Subjects}

The same 15 healthy male subjects (age $27.7 \pm 3.3$ years, weight $80.5 \pm 7.4 \mathrm{~kg}$, height $1.86 \pm 0.05 \mathrm{~m}, B M I$ $23.1 \pm 1.6 \mathrm{~kg} / \mathrm{m}^{2}$ ) of our previous study [33] participated in the present experiment. Prior to the experiment, all subjects read and signed an "informed consent" in which the objective and experimental protocol was explained. This study was approved by the Local Committee for Medical Ethics of the Roessingh Centre for Rehabilitation (Enschede, The Netherlands).

\section{B. Instrumentation}

Experiments were performed with a computer-aided simulator chair [Fig. 1(a)]. Spaced according to an average inter-tuberal distance of $120 \mathrm{~mm}$ [9], two force sensing support elements $(\varnothing 90 \mathrm{~mm})$ were integrated in the seating surface [Fig. 1(b)]. Both support elements were adjustable in height within a range of $40 \mathrm{~mm}$ below the seating surface $(-20 \pm 20 \mathrm{~mm})$. For accurate 3-D measurement of seat reaction load, 6 uni-axial load cells (FUTEK, CA) were mounted under the seat support. The support cushion was upholstered with $100 \mathrm{~mm}$ of industrial foam; $60 \mathrm{~mm}$ polyether SG40 on top of $40 \mathrm{~mm}$ polypress. Round cutouts were made in the cushion above the support elements, which were then upholstered with $50 \mathrm{~mm}$ polyether SG40 on top of $50 \mathrm{~mm}$ polypress. An external pressure mapping device (Teksan, Boston, MA) was placed over the seat surface. The device consisted of 1024 $(32 \times 32)$ square elements $(15 \times 15 \mathrm{~mm})$ and was calibrated with an upper limit of $33 \mathrm{kPa}$. The pressure elements were connected flexibly to minimize hammocking [34]. The force sensing seating plane (FSP) with integrated adjustable tuberal support elements (TSE) and external pressure mapping device (PMD) is shown in Fig. 1(b). Skin and subcutaneous subtuberal buttock tissue oxygenation and perfusion were simultaneously measured with two noninvasive fibre-optic probes [Fig. 1(c)] that we attached on the skin under the ITs. Both probes were connected with the O2C (Oxygen-to-see, LEA, Giessen, Germany) which is a diagnostic device that uses light-guide tissue spectrophotometry, a combination of laser Doppler flowmetry and diffuse reflectance spectroscopy, for simultaneous noninvasive measurement of oxygen supply in blood perfused tissue. Each probe incorporates Laser-Doppler and broadband light spectroscopy and was shaped with relative flat dimensions [Fig. 1(c)]. The probe under the left IT measured skin $(<2 \mathrm{~mm})$ oxygenation and perfusion, and the probe under the right IT measured subcutaneous $(<8 \mathrm{~mm})$ oxygenation and perfusion. Oxygenation levels in the skin and subcutaneous tissue were expressed as $S O 2_{s k}$ and $S O 2_{s c}$ respectively and reflect oxygen saturation of hemoglobin as a relative measure [\%]. Perfusion levels in the skin and subcutaneous tissue were expressed as $F_{s k}$ and $F_{s c}$ respectively and reflect the blood flow in the microcirculation as an arbitrary unit [au].

\section{Data Analysis}

The $x-z$ and $y-z$ planes of the global reference frame $(G)$ aligned, respectively, to the frontal and sagittal planes of the simulator chair. A seat coordinate frame $\left(R_{s}\right)$ was constructed 


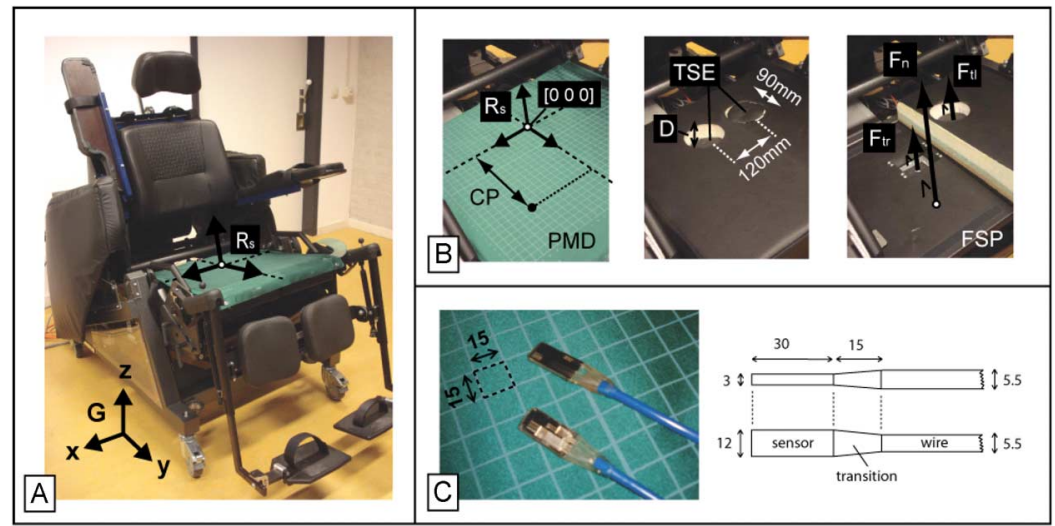

Fig. 1. Experimental setup. A: computer-aided adjustable simulator chair with the external PMD placed on the seat. The origin of the seat coordinate frame $\left(R_{s}\right)$ is located between the TSE. G defines the global reference frame. b: force sensing seating plane (FSP) with two round $(\varnothing 90 \mathrm{~mm})$ adjustable force sensing TSE spaced according to an inter-tuberal distance of $120 \mathrm{~mm}$. Maximal tuberal adjustment $(\mathrm{D}=-40 \mathrm{~mm})$ is shown. Centre of pressure $(\mathrm{CP})$ is expressed relative to the origin $\left[\begin{array}{lll}0 & 0 & 0\end{array}\right]$ and along the $y$-axis of $R_{s}$. The normal force on the seat $\left(F_{n}\right)$ and on the left and right TSE ( $F_{t 1}$ and $\left.F_{t r}\right)$ are derived from the FSP. $F_{t}=F_{t r}+F_{t l}$. C: Shape and dimensions of the noninvasive fibre-optic probes that we attached on the skin under the left and right ITs to measure subtuberal buttock tissue oxygenation and perfusion.

with the $x$-axis pointing to right, the $y$-axis pointing anteriorly parallel to the seat, and the $z$-axis pointing cranially perpendicular to the seat [Fig. 1(a) and (b)]. The origin of $R_{s}$ lies between the tuberal support areas. As a relative measure for tuberal load, a dispersion index $(D I)$ was calculated that expresses the load on the TSE relative to the total load on the seat. $D I_{f}$ was derived from the FSP according to (1) in which the normal force on the $\operatorname{TSE}\left(F_{t}\right)$ was divided by the normal force on the seat $\left(F_{n}\right)$. D $I_{p}$ was derived from the PMD according to (2) in which the sum of all pressure elements on the TSE was divided by the sum of all pressure elements on the seat support

$$
\begin{aligned}
D I_{f} & =F_{t} / F_{n} \\
D I_{p} & =\sum\left(P_{t}\right)_{i} / \sum\left(P_{s}\right)_{i} .
\end{aligned}
$$

Center of pressure $(C P)$ was expressed along the $y$-axis of $R_{s} . C P_{f}$ was derived from the FSP and $C P_{p}$ from the PMD. Buttock interface pressures distribution in seating conditions with fully loaded and unloaded ITs are shown in Fig. 2.

\section{Experimental Protocol}

Prior to the experiment, an empty seated force calibration zero-measurement was performed. Subjects were seated with their tuberosities on top of the adjustable support elements. Ischial peak pressure mapping was used to monitor the ITs when positioning the subject in the chair and aligning the anatomical sagittal plane with the global $y-z$ plane. The footrests were set perpendicular to the seat and adjusted in a way that the thighs were fully supported by the seat except for the popliteal space. The experiment involved four cycles of downward sinusoid tuberal support adjustments within a range of $40 \mathrm{~mm}$ $(-20 \pm 20 \mathrm{~mm})$ and a time period of $60 \mathrm{~s}$. Seat reaction forces, buttock interface pressure, tuberal adjustment $(D)$ and buttock tissue oxygenation $\left(S O 2_{s k}\right.$ and $\left.S O 2_{s c}\right)$ and perfusion $\left(F_{s k}\right.$ and $F_{s c}$ ) were captured and stored for offline analyses. Prior to the experiment, the initial values for all quantities were derived during a 1-min steady-state reference measurement with fully
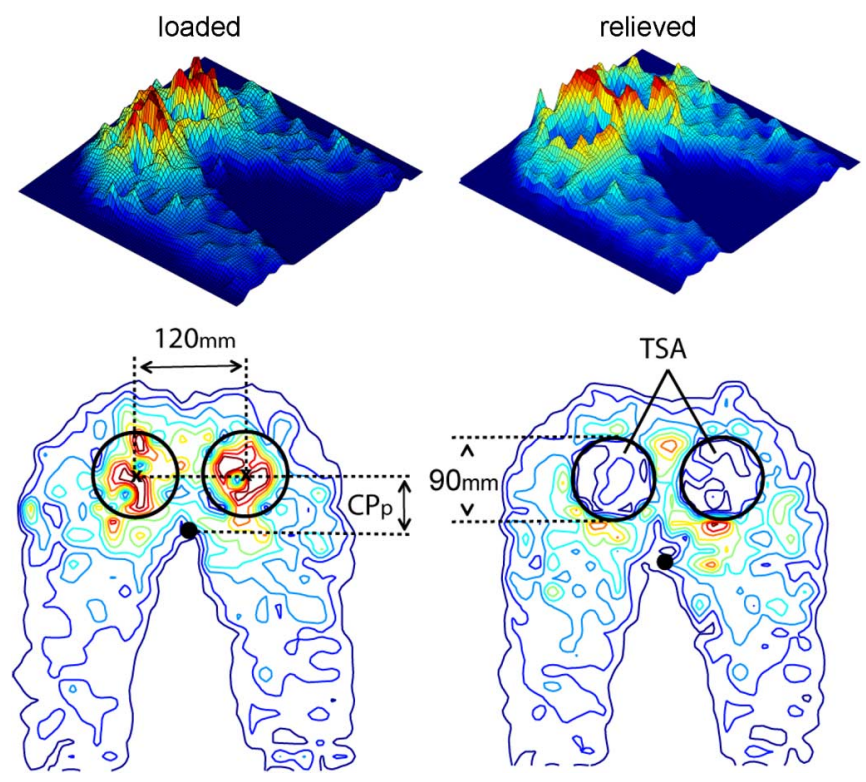

Fig. 2. Buttock interface pressure distribution as measured with the external pressure mapping device (PMD) in loaded and relieved seating conditions. Spaced according to an inter-tuberal distance of $120 \mathrm{~mm}$, two areas for tuberal support (TSA) are defined on top of the round $(\varnothing 90 \mathrm{~mm})$ adjustable tuberal support elements (TSE). Centre of pressure $\left(\mathrm{CP}_{\mathrm{p}}\right)$ was computed in forward direction relative to the middle of the TSA.

loaded ITs. Typical examples for $D, D I_{f}, D I_{p}, C P_{f}, C P_{p}$, $S O 2_{s k}, F_{s k}, S O 2_{s c}$, and $F_{s c}$ during TSE adjustment are shown in Fig. 3(a).

\section{E. Statistics}

The initial values (init $\pm \mathrm{sd}$ ) and ranges $(\Delta \pm \mathrm{sd}$ ) for all quantities $\left(D, D I_{f}, D I_{p}, C P_{f}, C P_{p}, S O 2_{s k}, F_{s k}, S O 2_{s c}\right.$, and $F_{s c}$ ) were derived and averaged over all subjects. To evaluate whether tuberal support adjustment is effective to regulate buttock load, all quantities were first normalized to its total range as shown in Fig. 3(b) for $S O 2_{s c}$. Normalized quantities for buttock load $\left(n D I_{f}, n D I_{p}, n C P_{f}, n C P_{p}, n S O 2_{s k}, n F_{s k}, n S O 2_{s c}\right.$ and $n F_{s c}$ ) were then related to the normalized tuberal adjustment 


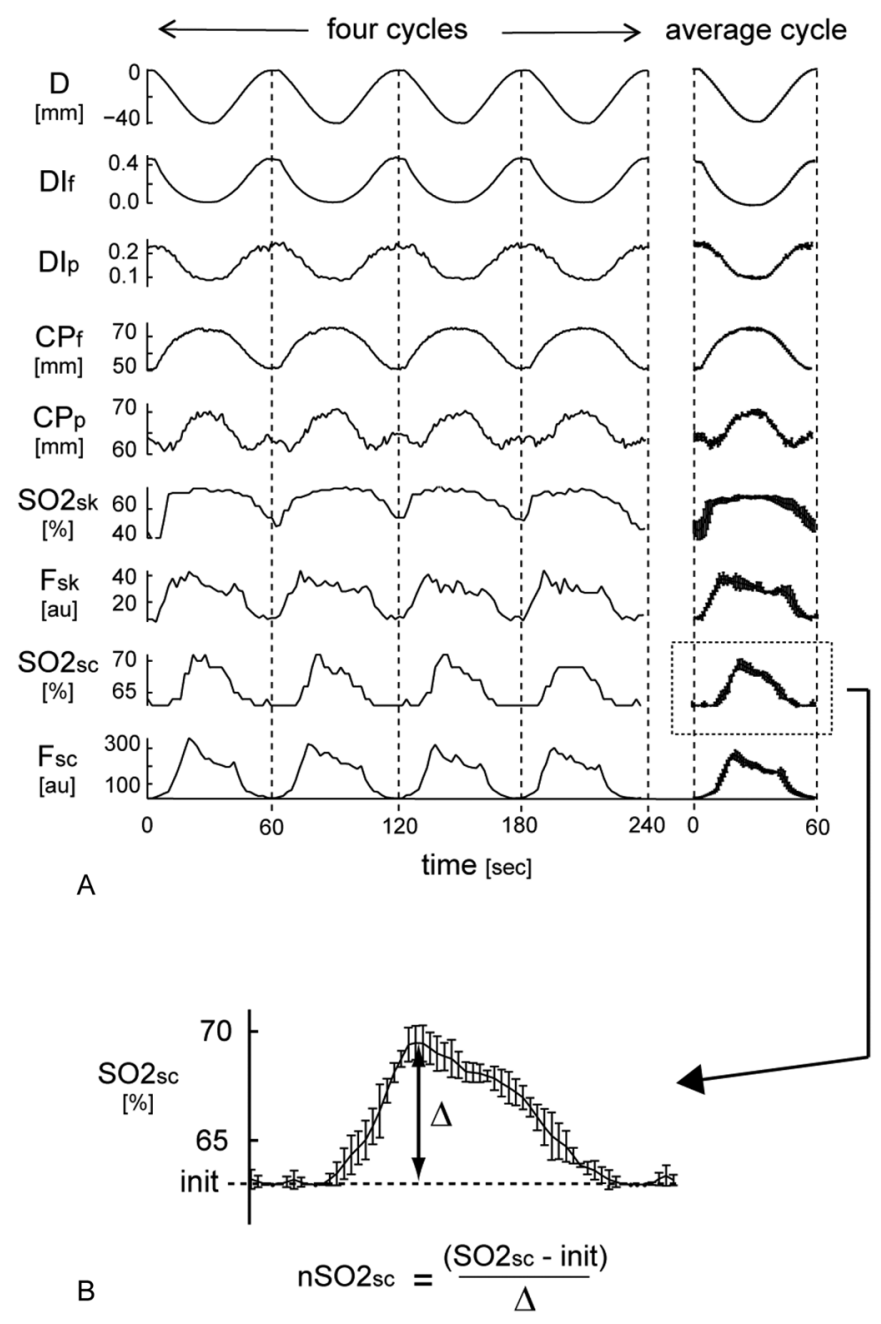

Fig. 3. A: Typical examples for measurement of $D, D_{f}, D_{p} C_{f}, C P_{p}$, $\mathrm{SO} 2_{\mathrm{sk}}, \mathrm{F}_{\mathrm{sk}}, \mathrm{SO} 2_{\mathrm{sc}}$ and $\mathrm{F}_{\mathrm{sc}}$ when adjusting the TSE within a range of $40 \mathrm{~mm}$ and a time period of $60 \mathrm{~s}$. B: All quantities were normalized as shown for $\mathrm{SO} 2_{\mathrm{sc}}$.

$(n D)$. Linear relations were assumed and the coefficients of correlation $(r)$ with accompanying significance $(p)$ were derived. We then calculated the coefficients of determination $\left(r^{2}\right)$ which gives us an indication about the strength of the relation.

\section{RESULTS}

During TSE adjustment, the initial values and ranges were computed for all quantities and averaged over all subjects (Table I). Note that the number of trials is smaller for measurement of tissue oxygenation and perfusion $\left(S O 2_{s k}, F_{s k}\right.$, $S O 2_{s c}$, and $\left.F_{s c}\right)$. Five out of 15 subjects showed no response in buttock tissue oxygenation and perfusion when adjusting the tuberal support elements (TSE). This group was excluded for analysis because the average values for $S O 2_{s k}, F_{s k}, S O 2_{s c}$ or $F_{s c}$ during the experiment were not significantly different than the initial values.

Normalized quantities for buttock load were related to the normalized TSE adjustment. Linear relations were assumed and the coefficients of correlation $(r)$ with accompanying significance $(p)$ were derived and shown in Table I. Coefficients of determination $\left(r^{2}\right)$ were calculated as an indication about the strength of the relation.
TABLE I

InITIAL VALUES (initial $\pm \mathrm{sd}$ ), RANGeS $(\Delta \pm \mathrm{sd}$ ), COEFFICIENT OF CORRELATION ( $r$ AND COEFFICIENTS OF DETERMINATION $\left(\mathrm{r}^{2}\right)$ FOR $\mathrm{D}, \mathrm{DI}_{\mathrm{f}}, \mathrm{DI}_{\mathrm{p}} \mathrm{CP}_{\mathrm{f}}, \mathrm{CP}_{\mathrm{p}}, \mathrm{SO} 2_{\mathrm{sk}}, \mathrm{F}_{\mathrm{sk}}, \mathrm{SO} 2_{\mathrm{sc}}, \mathrm{AND} \mathrm{F}_{\mathrm{sc}}$

\begin{tabular}{llllll}
\hline \hline & & init \pm sd & $\Delta \pm$ sd & $\mathrm{r}$ & $\mathrm{r}^{2}$ \\
\hline $\mathrm{D}$ & {$[\mathrm{mm}]$} & $0 \pm 0$ & $40 \pm 0$ & $1.00^{*-}$ & 1.00 \\
$\mathrm{DI}_{\mathrm{f}}$ & {$[-]$} & $0.36 \pm 0.6$ & $0.36 \pm 0.6$ & $0.97^{*}$ & 0.94 \\
$\mathrm{DI}_{\mathrm{p}}$ & {$[-]$} & $0.22 \pm 0.2$ & $0.16 \pm 0.2$ & $0.98^{*}$ & 0.95 \\
$\mathrm{CP}_{\mathrm{f}}$ & {$[\mathrm{mm}]$} & $59 \pm 14$ & $20 \pm 2$ & $-0.96^{*}$ & 0.92 \\
$\mathrm{CP}$ & {$[\mathrm{mm}]$} & $58 \pm 9$ & $11 \pm 2$ & $-0.88^{*}$ & $0.78 \quad \mathrm{n}=15$ \\
\hline $\mathrm{SO} 2_{\text {sk }}$ & {$[\%]$} & $41 \pm 22$ & $42 \pm 27$ & $-0.73^{*}$ & 0.54 \\
$\mathrm{~F}_{\text {sk }}$ & {$\left[\mathrm{au}{ }^{1}\right]$} & $9 \pm 15$ & $98 \pm 63$ & $-0.74^{*}$ & 0.54 \\
$\mathrm{SO}_{\text {sc }}$ & {$[\%]$} & $62 \pm 3$ & $9 \pm 5$ & $-0.86^{*}$ & $0.74 \quad$ \\
$\mathrm{~F}_{\mathrm{sc}}$ & {$\left[\mathrm{auu}{ }^{1}\right]$} & $102 \pm 56$ & $323 \pm 160$ & $-0.80^{*}$ & $0.64 \quad \mathrm{n}=10$ \\
\hline
\end{tabular}
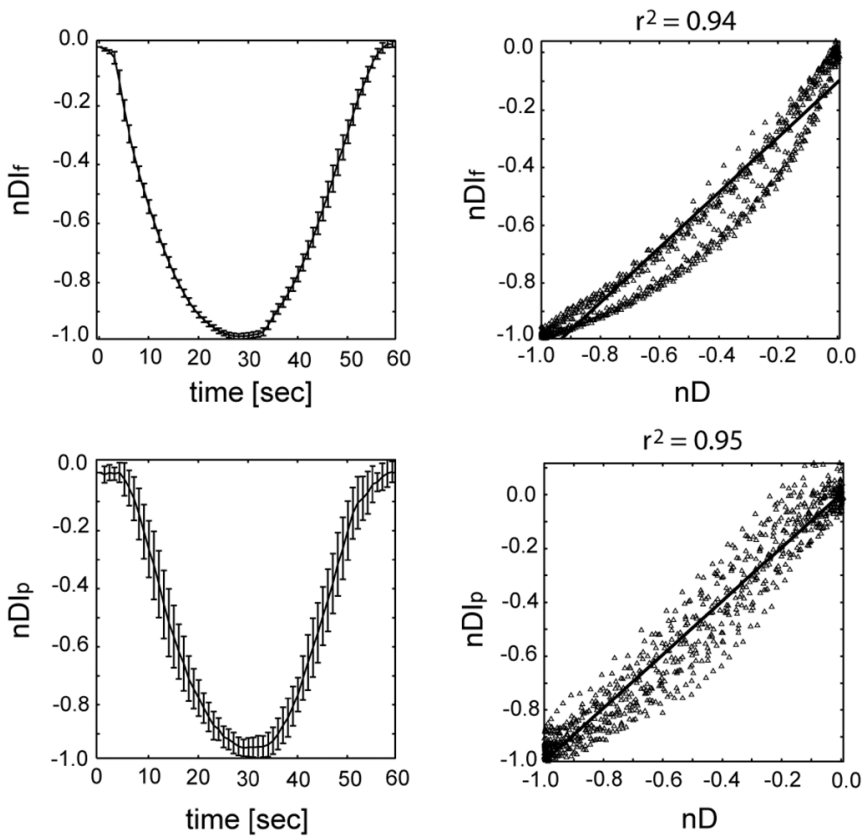

Fig. 4. Left: $\mathrm{nDI}_{\mathrm{f}}$ and $\mathrm{nDI}_{\mathrm{p}}$ in time. Right: $\mathrm{nDI}_{\mathrm{f}}$ and $\mathrm{nDI}_{\mathrm{p}}$ related to $\mathrm{nD}$. Linear relations were assumed and coefficients of determination $\left(\mathrm{r}^{2}\right)$ were derived.

In Fig. 4, the left graphs reflect $n D I_{f}$ and $n D I_{p}$ in time. The right graphs show how $n D I_{f}$ and $n D I_{p}$ are related to $n D$. Path-dependent hysteresis effects are shown for $n D I_{f}$ when adjusting the TSE up- and downward. The inter-individual variability (error-bars) was larger for $n D I_{p}$ than for $n D I_{f}$.

In Fig. 5, the left graphs reflect $n C P_{f}$ and $n C P_{p}$ in time. The right graphs show how $n C P_{f}$ and $n C P_{p}$ are related to $n D$. The inter-individual variability (error-bars) was larger for $n C P_{p}$ than for $n C P_{f}$. Similar to the effect on $n D I_{f}$, hysteresis is also shown for $n C P_{f}$. During the first and last $10 \mathrm{~s}$ of the adjustment cycle $(-0.2<n D<0.0)$, the effect on $n C P_{p}$ seems opposite to what was found during the rest of the cycle.

The effects of TSE adjustment $(n D)$ on levels of oxygenation and perfusion in the skin $\left(n S O 2_{s k}\right.$ and $\left.n F_{s k}\right)$ and subcutaneous $\left(n S O 2_{s c}\right.$ and $n F_{s c}$ ) subtuberal buttock tissue are shown in Fig. 6. All normalized quantities of blood supply were inversely related to $n D$. Variability between subjects is indicated with error bars. 

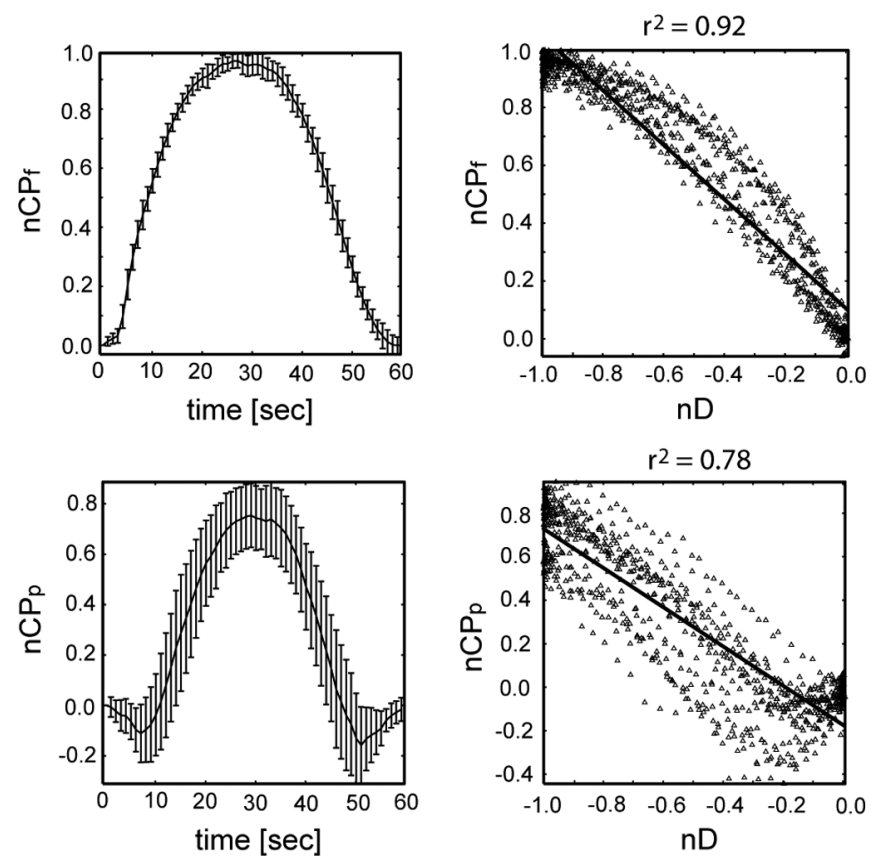

Fig. 5. Left: $\mathrm{nCP}_{\mathrm{f}}$ and $\mathrm{nCP}_{\mathrm{p}}$ in time. Right: $\mathrm{nCP}_{\mathrm{f}}$ and $\mathrm{nCP}_{\mathrm{p}}$ related to $\mathrm{nD}$. Linear relations were assumed and coefficients of determination $\left(r^{2}\right)$ were derived.

\section{DISCUSSION}

This study investigated the redistribution of external buttock load in relation to the pattern (i.e., dynamics) of subtuberal blood supply in sitting with a dynamic tuberal support of $1 / 60$ $\mathrm{Hz}(80 \mathrm{~mm} / \mathrm{min})$.

When adjusting the TSE below the seating surface, significant effects were found on the contact load under the ITs, centre of buttock pressure $(C P)$ and the subtuberal buttock tissue oxygenation $\left(S O 2_{s k}\right.$ and $\left.S O 2_{s c}\right)$ and perfusion $\left(F_{s k}\right.$ and $F_{s c}$ ). Downward TSE adjustment relieved the external tuberal load almost completely and shifted $\mathrm{CP}$ in forward direction. High coefficients of determination $\left(r^{2}>0.7\right)$ were found for $D I$ and $C P$ which indicate a strong relation with the level of tuberal support and suggested that the external ischial buttock load is regulable from TSE adjustment.

For most subjects, the level of oxygenation and perfusion in the subtuberal buttock tissue increased significantly when unloading the TSE. However, weak coefficients of determination $\left(r^{2}<0.7\right)$ indicates large variability between subjects. Individual differences in the dynamics/response of blood supply during support surface manipulations make precise regulation of skin and subcutaneous tissue oxygenation and perfusion difficult.

Differences in external buttock load as measured with the conventional PMD and the FSP could be ascribed to inaccuracies in PMD measurement under fully loaded seating conditions. When the TSEs were level with the seating surface, very high forces exerted on the pressure elements under the ITs. We observed that some elements could not resist such high contact loads and started saturating or even fail measuring. Due to this phenomenon, the tuberal interface pressure as measured with PMD was underestimated.
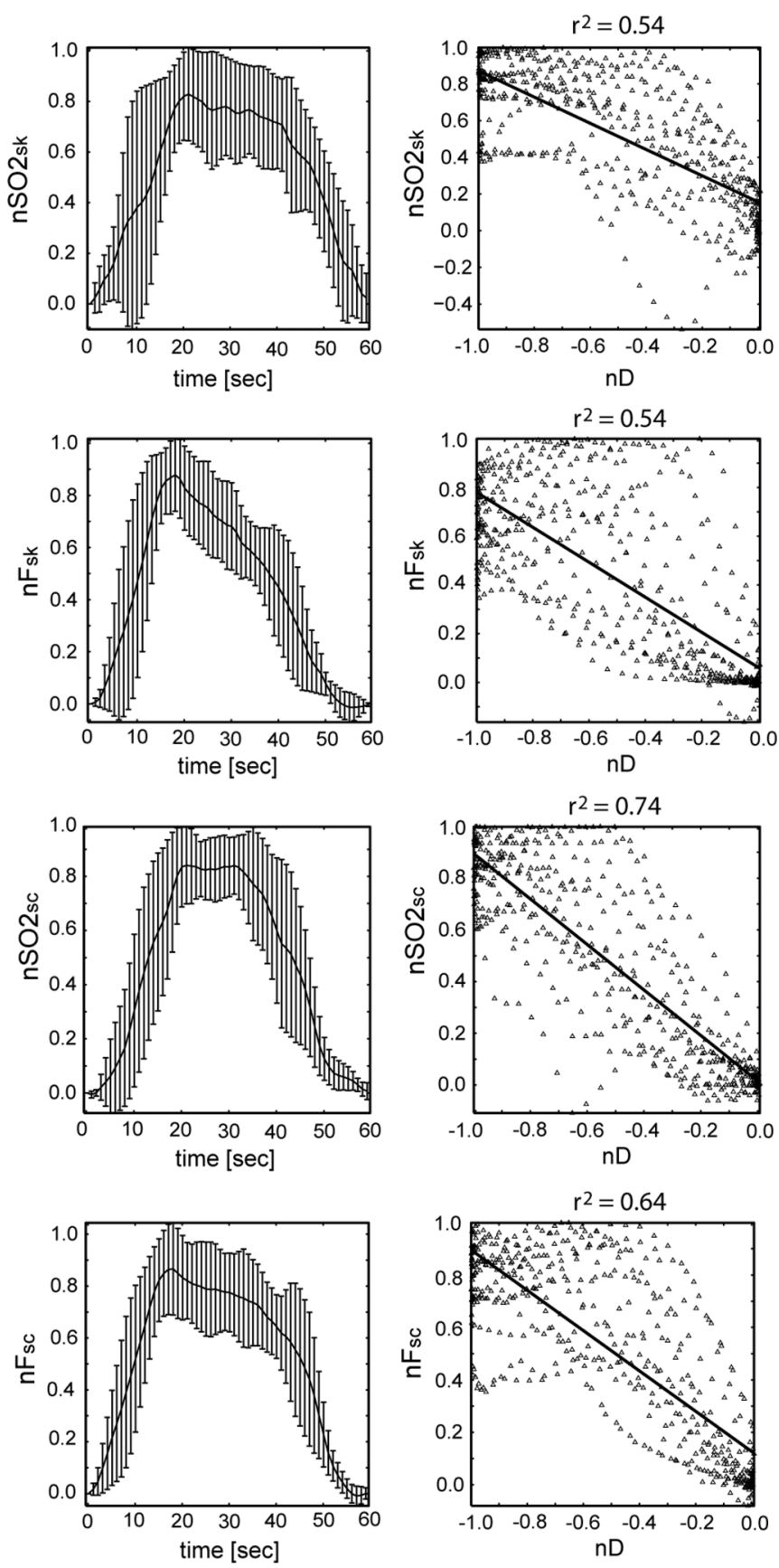

Fig. 6. Left: $\mathrm{nSO}_{2 \mathrm{~s}} \mathrm{k}, \mathrm{n}_{\mathrm{Fs}} \mathrm{k}, \mathrm{nSO}_{2 \mathrm{~s}} \mathrm{c}, \mathrm{n}_{\mathrm{Fs}} \mathrm{c}$ in time. Right: $\mathrm{nSO}_{2 \mathrm{~s}} \mathrm{k}, \mathrm{n}_{\mathrm{Fs}} \mathrm{k}$, $\mathrm{nSO}_{2 \mathrm{~s}} \mathrm{c}, \mathrm{nFsc}$ related to $\mathrm{nD}$. Linear relations were assumed and coefficients of determination $\left(\mathrm{r}^{2}\right)$ were derived.

The pressure elements of PMD were connected flexibly to minimize hammocking [34]. However, buttock load did not relieve entirely under the ITs when the TSE were lowered. Limited flexibility of PMD caused that some tuberal pressure was maintained at all times. Because the PMD was placed on top of the FSP, the latter measured entire tuberal pressure relief since the TSE completely lost contact with the buttock/PMD interface. Hammocking at the seat interface when the ITs were unloaded and inaccurate peak pressure readings when the tuberosities were fully loaded explain the differences in measurement between $C P_{f}$ and $C P_{p}$ and between $\mathrm{DI}_{\mathrm{f}}$ and $\mathrm{DI}_{\mathrm{p}}$, as shown in Table I. 
Some interesting differences in measurement with the PMD and FSP were also observed during TSE adjustment. First, large variability (error-bars) was measured for $n D I_{p}$ and $n C P_{p}$, which suggested that the reproducibility for PMD measurement was less than for the FSP. Second, path-dependent hysteresis for $n D I_{f}$ and $n C P_{f}$ was observed when adjusting the TSE. Because the force elements of the FSP were located underneath the seating cushion, we ascribed these effects to friction between the seating cushion and the TSE. In loaded seating conditions, the cushions on top of the TSE expanded sideways and contacted the surrounding seating cushion. Although the cushions on the TSE were designed not to contact the surrounding cushion in loaded seating conditions, small levels of friction still occurred when adjusting the TSE upand downward. Third, when adjusting the TSE just below the seating surface, the PMD did not monitor pressure change on the TSE due to saturation and failing of some pressure elements that were located directly underneath the ITs. As a result, $C P_{p}$ did not shift forward in the first stage of tuberal unloading. This phenomenon is less profound for $D I_{p}$ because the dispersion index is not an absolute measure but expresses the tuberal interface pressure relative to the total buttock interface pressure.

Reliability problems when quantifying buttock load with absolute peak pressure measurement have also been reported in other studies [35], [36]. Relative measures have therefore been developed that expresses absolute peak pressures relative to the total buttock pressure. Because better test-retest reliabilities have been reported, it is often proposed to use relative measures to quantify pressure distribution [35], [37]. Despite using relative measures, our findings suggest that hammocking at the seat interface and inaccurate peak pressure measurement could still lead to misinterpretation of the buttock interface pressure distribution.

Because the external buttock load does not provide direct information about the internal tissue conditions, additional measurement of the ischial blood supply has been suggested as being useful to evaluate the viability of internal buttock tissue [2]. However, clinical evaluation of the microcirculation in the subcutaneous tissue is difficult and most available measuring techniques (e.g., laser Doppler flowmetry, transcutaneous oxygen tension, tissue reflectance spectrometry and thermography) struggle with technical limitations concerning measuring depth and reliability problems. Light-guide tissue spectrophotometry is a relatively new technique to evaluate micro-vascular tissue perfusion and has been developed to facilitate observation of tissue viability during surgery [38], [39]. The effectiveness of this technique has also been demonstrated in early identification and quantification of tissue ischemia in diabetic foot ulcers [40], [41]. Most diagnostic devices that measure tissue perfusion and oxygenation are limited to a measuring depth of 1 or $2 \mathrm{~mm}$, which makes that most studies focus on the effects of external buttock load on tissue oxygenation and perfusion of the skin only. The device that was used in the present study could monitor tissue oxygenation and perfusion up to a measuring depth of approximately $8 \mathrm{~mm}$. This provides more insight in tissue regions closer to places of interests than what normally could be reached.
For 10 out of all 15 subjects we found that oxygenation and perfusion were inversely related to the applied loads under the ITs and that the perfusion and oxygenation values of the skin were more sensitive to the induced tuberal adjustments than what was measured in the subcutaneous buttock tissue. Because the induced tissue deformations are better distributed when travelling into deeper tissue regions, less internal stress/strain fluctuations are expected in comparison to the skin. This rather limited effect on the internal mechanical tissue properties indicates that the initial seating conditions are of great importance. When the initial shear force and pressure gradients within the tissue are relatively high from the start, and the subtuberal buttock tissue already involves questionable levels of blood supply, it is uncertain whether periodic pressure relief allows full recovery of the ischial buttock tissue after prolonged deformation. In some subjects we even observed that the flow of blood in the microcirculation of the skin completely stagnated, which indicated that the superficial arteries entirely collapsed. Interference of the probes in the tuberal zone probably intensified this effect. Future experiments must evaluate whether it is useful to surround the probes with a (silicon) mold shaped around the buttock tissue under the ITs. This way, the contact load equally distributes over the ITs and less interference with the ischial buttock tissue is expected.

Five subjects showed no significant response in buttock tissue perfusion and oxygenation, and were classified as nonresponding subjects. We already speculated about this phenomenon in our previous study [33]. Similar nonresponding patterns were reported by Bader [27] when investigating the effects of dynamic cushions on skin perfusion in healthy and impaired subjects. He reported that the nonresponding group might be subjected to an increased risk for tissue ischemia due to a potential impaired physiological control mechanism. However, in our studies the opposite might be true since the initial levels of tissue perfusion involve higher values for the nonresponding group compared to the responding group. This could indicate that the nonresponders have less risk for deep tissue injury because they already experience relatively good perfusion levels. Their physiological control mechanism potentially allows them to maintain blood flow, even when the ischial buttock tissue is fully loaded. This could benefit the tissue viability and decreases the risk for pressure ulcer formation in continuous static sitting.

Another explanation could be that the probes simply did not measure the area where the most deformation occurred. When the area of blood flow stagnation shifted to tissue regions just beyond the reach of the measurement probes, no effect on oxygenation and perfusion levels will be found.

Future studies must address more attention to this matter. In-depth investigation about the physiological effects of tissue loading on ischial blood supply in healthy subjects and in impaired subjects with high and low risk for pressure ulcers might reveal whether the differences in blood pattern is linked to differences in the physiological mechanism that controls the supply of blood in the buttock tissue in loaded and unloaded seating conditions.

For all responding subjects, the response in tissue oxygenation and perfusion could roughly be divided into three stages (Fig. 6). Strong hyperaemia effects were observed in the first 
stage. Unloading the ITs induced significant increase in skin and subcutaneous tissue oxygenation and perfusion. A moderate overshoot in blood flow occurs due to temporary ischemia and build-up blood pressure from preceding tissue deformation. The second stage showed that from a certain point, downward tuberal adjustments were no longer accompanied with an increase in blood supply. We even observed a gradual outflow of blood which we ascribe to the overshoot in the beginning of the second stage. The last (third) stage represents a strong decrease in oxygenation and perfusion when reloading the ITs.

Upward TSE adjustments were accompanied with a strong outflow of blood which was caused by occlusion of blood vessels when the buttock load under the ITs gradually increased. Rapid inflow of blood in the initial stage of tuberal unloading followed by a more gradual outflow in the rest of the movement cycle indicates that the average blood supply increases when the adjustment frequency increases. This might explain the outcomes of our previous study [33], which showed a trend $(p>0.05)$ of higher average values for skin oxygenation and subcutaneous tissue perfusion in seating conditions with higher adjustment frequencies.

We must take in mind that ischemia-reperfusion injury can occur from the reperfusion of blood to previously ischemic tissue [42], [43]. During prolonged ischemia, the depletion of oxygen changes the metabolism from aerobic to anaerobic. As a result, the concentration of glucose reduces and tissue acidification occurs due to the accumulation of lactic acid [18]. Reperfusion of oxygen-derived free-radicals into the hypoxic acidified tissue after unloading, potentially initiate a cascade of harmful events that could result in tissue necrosis. However, we do not expect that this will happen during periodic TSE adjustment of $80 \mathrm{~mm} / \mathrm{min}$, since the time of ischemia is not long enough to completely deprive the tissue from its oxygen and to acidify the interstitial fluid. This way, the tissue remains invulnerable for the inflow of free-radical and less damage is expected.

The composition of the cushion on the TSE was slightly different compared to the rest of the support surface. This was done because the stiffness of the support surface alters when cutting out two round holes. Due to the loss of surface tension, the stiffness of the cushion reduces when coming closer to the cutouts. The stiffness on the TSEs reduces even more due to the complete loss of surface tension. We, therefore, modified the TSE upholstering and slightly increased its stiffness. This gave the impression of sitting on a hard surface when the TSE were level with the seating surface. This especially applied for individuals who were thin and had less ischial buttock tissue to distribute the interface pressure over a larger contact area. Depending on the mechanical characteristics of the support cushion, it has been reported that the peak pressures under the ITs could be $30 \%$ higher in thin $\left(\mathrm{BMI}<20 \mathrm{~kg} / \mathrm{m}^{2}\right)$ individuals than in "normal" (BMI $20-25 \mathrm{~kg} / \mathrm{m}^{2}$ ) individuals [44]. Although less profound, we also observed some influence of body build on buttock pressure distribution. Under fully loaded seating conditions we found that for individuals with a thin body type the TSE supported up to $40 \%$ of all seating load. When such high forces are locally exerted on the buttock tissue under the tuberosities, significant deformation of the skin and subcutaneous tissue is expected. As a consequence, we found that for some individuals the supply of blood completely stagnated and the level of skin oxygenation and perfusion decreased to zero. Such extreme seating conditions, in which ischemia is combined with excessive internal tissue deformation due to high external load, must be prevented at all times because it aggravates the extent and onset of tissue damage within very short periods of exposure [18].

During downward TSE adjustment, the contact load is relieved under the ITs and shifted towards the edges of the cushion cutouts where it exerted on the surrounding tissue regions such as the thighs and sacrum. That TSE adjustment not only affects the buttock tissue under the ITs is clearly shown in Fig. 2. During the unloading phase, high shear forces and pressure gradients were introduced in the tissue around the ITs. Adjustment of the TSE must therefore be applied periodically to prevent tissue damage in the surrounding tissue as well.

It is very hard to predict how long the ischial buttock tissue can sustain certain deformation before tissue degeneration takes place, and how often the TSE must be adjusted to maintain tissue viability in prolonged static sitting. Several researchers have taken much trouble to identify reliable thresholds for minimal pressure and duration which consistently generates tissue necrosis [1], [15], [18]. However, no reliable and clinically applicable indicator has yet been found that predicts the risk for pressure ulcers from continuous deformation. Until this has been revealed, the U.S. Department of Health recommends individuals in a wheelchair to relieve buttock pressure every $15 \mathrm{~min}$ [45]. Whether it is sufficient to maintain adequate buttock tissue viability in prolonged static wheelchair sitting by adjusting the TSE every $15 \mathrm{~min}$ is something we have to evaluate.

\section{CONCLUSION}

TSE adjustment seemed effective to regulate centre of buttock pressure and the dispersion index under the ITs. Differences in measurement with the FSP and PMD have been found. Hammocking at the seat interface and inaccurate peak pressure readings could misinterpret pressure distribution as measured with the PMD.

Blood supply to the subtuberal buttock tissue was inversely related to the applied loads under the ITs. A rapid inflow of blood in the initial stage of tuberal unloading followed by a more gradual outflow in the rest of the movement cycle indicates that the average blood supply increases when the adjustment frequency increases.

Furthermore, TSE adjustment not only affected the buttock tissue under the ITs but also the tissue under the sacrum and thighs. This suggests a potential benefit for buttock tissue viability under the whole ischial region.

How TSE adjustment influences external buttock load and the dynamics of blood supply to the (subtuberal) buttock tissue in impaired individuals is still to be investigated.

\section{ACKNOWLEDGMENT}

The authors would like to thank the engineering company Demcon (Oldenzaal, The Netherlands) for developing the experimental simulator chair. 


\section{REFERENCES}

[1] C. V. Bouten, C. W. Oomens, F. P. Baaijens, and D. L. Bader, "The etiology of pressure ulcers: Skin deep or muscle bound?" Arch. Phys. Med. Rehabil., vol. 84, pp. 616-619, 2003.

[2] J. Black, M. Baharestani, J. Cuddigan, B. Dorner, L. Edsberg, D. Langemo, M. E. Posthauer, C. Ratliff, and G. Taler, NPUAP, "National Pressure Ulcer Advisory Panel's updated pressure ulcer staging system," Urologic Nursing, vol. 27, pp. 144-150, 2007.

[3] P. R. Quintavalle, C. H. Lyder, P. J. Mertz, C. Phillips-Jones, and M. Dyson, "Use of high-resolution, high-frequency diagnostic ultrasound to investigate the pathogenesis of pressure ulcer development," $A d v$. Skin Wound Care, vol. 19, pp. 498-505, 2006.

[4] J. Reswick and J. Rogers, "Experience at Rancho Los Amigos Hospital with devices and techniques to prevent pressure sores," in Bedsore Biomechanics, R. M. Kennedy, J. M. Cowden, and J. T. Scales, Eds. London, U.K.: McMillan, 1976, pp. 301-310.

[5] D. Gawlitta, C. W. Oomens, D. L. Bader, F. P. Baaijens, and C. V. Bouten, "Temporal differences in the influence of ischemic factors and deformation on the metabolism of engineered skeletal muscle," J. Appl. Physiol., vol. 103, pp. 464-473, 2007.

[6] A. Gefen, L. H. Cornelissen, D. Gawlitta, D. L. Bader, and C. W. Oomens, "The free diffusion of macromolecules in tissue-engineered skeletal muscle subjected to large compression strains," J. Biomechan. vol. 41, pp. 845-853, 2008.

[7] D. Gawlitta, K. J. Boonen, C. W. Oomens, F. P. Baaijens, and C. V. Bouten, "The influence of serum-free culture conditions on skeletal muscle differentiation in a tissue-engineered model," Tissue Eng. Part A, vol. 14, pp. 161-171, 2008.

[8] A. Gefen, B. van Nierop, D. L. Bader, and C. W. Oomens, "Strain-time cell-death threshold for skeletal muscle in a tissue-engineered model system for deep tissue injury," J. Biomechan., vol. 41, pp. 2003-2012, 2008.

[9] E. Linder-Ganz, N. Shabshin, Y. Itzchak, and A. Gefen, “Assessment of mechanical conditions in sub-dermal tissues during sitting: A combined experimental-MRI and finite element approach," J. Biomechan., vol. 40, pp. 1443-1454, 2007.

[10] T. Brosh and M. Arcan, "Modeling the body/chair interaction - an integrative experimental-numerical approach," Clin. Biomechan., vol. 15, pp. 217-219, 2000.

[11] R. Ragan, T. W. Kernozek, M. Bidar, and J. W. Matheson, "Seat-interface pressures on various thicknesses of foam wheelchair cushions: A finite modeling approach," Arch. Phys. Med. Rehab., vol. 83, pp. $872-875,2002$

[12] B. A. Todd and J. G. Thacker, "Three-dimensional computer model of the human buttocks, in vivo," J. Rehab. Res. Develop., vol. 31, pp. 111-119, 1994.

[13] D. Lim, F. Lin, R. W. Hendrix, B. Moran, C. Fasanati, and M. Makhsous, "Evaluation of a new sitting concept designed for prevention of pressure ulcer on the buttock using finite element analysis," Med. Biol. Eng. Comput., vol. 45, pp. 1079-1084, 2007.

[14] M. Makhsous, D. Lim, R. Hendrix, J. Bankard, W. Z. Rymer, and F. Lin, "Finite element analysis for evaluation of pressure ulcer on the buttock: Development and validation," IEEE Trans. Neural Syst. Rehab. Eng., vol. 15, no. 4, pp. 517-525, Dec. 2007.

[15] E. Linder-Ganz, S. Engelberg, M. Scheinowitz, and A. Gefen, "Pressure-time cell death threshold for albino rat skeletal muscles as related to pressure sore biomechanics," J. Biomechan., vol. 39, pp. 2725-2732, 2006.

[16] A. Stekelenburg, C. W. Oomens, G. J. Strijkers, L. de Graaf, D. L. Bader, and K. Nicolay, "A new MR-compatible loading device to study in vivo muscle damage development in rats due to compressive loading," Med. Eng. Phys., vol. 28, pp. 331-338, 2006.

[17] T. Ohura, N. Ohura, and H. Oka, "Incidence and clinical symptoms of hourglass and sandwich-shaped tissue necrosis in stage IV pressure ulcers," Wounds, vol. 19, pp. 310-319, 2007.

[18] A. Stekelenburg, D. Gawlitta, D. L. Bader, and C. W. Oomens, "Deep tissue injury: How deep is our understanding?," Arch. Phys. Med. Rehab., vol. 89, pp. 1410-1413, 2008.

[19] A. Stekelenburg, G. J. Strijkers, H. Parusel, D. L. Bader, K. Nicolay, and C. W. Oomens, "Role of ischemia and deformation in the onset of compression-induced deep tissue injury: MRI-based studies in a rat model," J. Appl. Physiol., vol. 102, pp. 2002-2011, 2007.

[20] R. Whittemore, "Pressure-reduction support surfaces: A review of the literature," J. Wound, Ostomy Continence Nursing, vol. 25, pp. 6-25, 1998.
[21] D. M. Brienza, K. C. Chung, C. E. Brubaker, J. Wang, T. E. Karg, and C. T. Lin, "A system for the analysis of seat support surfaces using surface shape control and simultaneous measurement of applied pressures,” IEEE Trans. Rehab. Eng., vol. 4, no. 2, pp. 103-113, Jun. 1996.

[22] R. J. Kwiatkowski and R. M. Inigo, "A closed loop automated seating system,” J. Rehab. Res. Develop., vol. 30, pp. 393-404, 1993.

[23] D. M. Brienza, R. M. Inigo, K. C. Chung, and C. E. Brubaker, "Seat support surface optimization using force feedback," IEEE Trans. Biomed. Eng., vol. 40, no. 1, pp. 95-104, Jan. 1993.

[24] D. M. Brienza, P. E. Karg, and C. E. Brubaker, "Seat cushion design for elderly wheelchair users based on minimization of soft tissue deformation using stiffness and pressure measurements," IEEE Trans. Rehab. Eng., vol. 4, pp. 320-327, Dec. 1996.

[25] M. Makhsous, D. M. Rowles, W. Z. Rymer, J. Bankard, E. K. Nam, D. Chen, and F. Lin, "Periodically relieving ischial sitting load to decrease the risk of pressure ulcers," Arch. Phys. Med. Rehab., vol. 88, pp. 862-870, 2007.

[26] L. Stockton and S. Rithalia, "Is dynamic seating a modality worth considering in the prevention of pressure ulcers?," J. Tissue Viabil., vol. 17, pp. 15-21, 2007.

[27] D. L. Bader, "The recovery chatacteristics of soft tissues following repetead loading," J. Rehab. Res. Develop., vol. 27, pp. 141-150, 1990.

[28] P. van Geffen and J. Reenalda, "DYNASIT: An assistive seating system that controls sitting posture and regulates body load associated with sitting related mobility problems," presented at the RESNA, Washington, 2008.

[29] C. W. Oomens, O. F. Bressers, E. M. Bosboom, C. V. Bouten, and D. L. Blader, "Can loaded interface characteristics influence strain distributions in muscle adjacent to bony prominences?," Comput. Methods Biomechan. Biomed. Eng., vol. 6, pp. 171-180, 2003.

[30] E. Linder-Ganz, N. Shabshin, Y. Itzchak, Z. Yizhar, I. Siev-Ner, and A. Gefen, "Strains and stresses in sub-dermal tissues of the buttocks are greater in paraplegics than in healthy during sitting," J. Biomechan., 2007.

[31] E. Linder-Ganz, G. Yarnitzky, S. Portnoy, Z. Yizhar, and A. Gefen, "Real-time finite element monitoring of internal stresses in the buttock during wheelchair sitting to prevent pressure sorces: Verification and phantom results," presented at the International Conference on Computational Bioengineering, Lisabon, Portugal, 2005.

[32] D. Mathieu and R. Mani, "A review of the clinical significance of tissue hypoxia measurements in lower extremity wound management," Int. J. Lower Extremity Wounds, vol. 6, pp. 273-283, 2007.

[33] J. Reenalda, "Dynamic sitting to prevent pressure ulcers in spinal cord injured," Ph.D. dissertation, Univ. Twente, Enschede, The Netherlands, 2009.

[34] V. Casey, S. Griffin, and S. B. O'Brien, “An investigation of the hammocking effect associated with interface pressure measurements using pneumatic tourniquet cuffs," Med. Eng. Phys., vol. 23, pp. 511-517, 2001.

[35] S. Sprigle, W. Dunlop, and L. Press, "Reliability of bench tests of interface pressure," Assistive Technol., vol. 15, pp. 49-57, 2003.

[36] M. Stinson, A. Porter, and P. Eakin, "Measuring interface pressure: A laboratory based investigation into the effects of repositioning and sitting," Am. J. Occupational Therapy, vol. 56, pp. 185-190, 2002.

[37] H. A. M. Staarink, "Sitting posture, comfort and pressure," in Faculty of Industrial Design Engineering. Delft, The Netherlands: Delft Univ. Technol., 1995.

[38] F. Holzle, D. J. Loeffelbein, D. Nolte, and K. D. Wolff, "Free flap monitoring using simultaneous non-invasive laser Doppler flowmetry and tissue spectrophotometry," J. Cranio-Maxillofacial Surgery, vol. 34, pp. 25-33, 2006.

[39] F. Holzle, S. Swaid, D. Nolte, and K. D. Wolff, "Nutritive perfusion at donor site after microvascular fibula transfer," Microsurgery, vol. 23, pp. 306-312, 2003.

[40] S. M. Rajbhandari, N. D. Harris, S. Tesfaye, and J. D. Ward, "Early identification of diabetic foot ulcers that may require intervention using the micro lightguide spectrophotometer," Diabetes Care, vol. 22, pp. 1292-1295, 1999.

[41] S. Beckert, M. B. Witte, A. Konigsrainer, and S. Coerper, "The impact of the Micro-Lightguide $\mathrm{O} 2 \mathrm{C}$ for the quantification of tissue ischemia in diabetic foot ulcers," Diabetes Care, vol. 27, pp. 2863-2867, 2004.

[42] S. Tsuji, S. Ichioka, N. Sekiya, and T. Nakatsuka, "Analysis of ischemia-reperfusion injury in a microcirculatory model of pressure ulcers," Wound Repair Regeneration, vol. 13, pp. 209-215, 2005.

[43] S. M. Peirce, T. C. Skalak, and G. T. Rodeheaver, "Ischemia-reperfusion injury in chronic pressure ulcer formation: A skin model in the rat," Wound Repair Regeneration, vol. 8, pp. 68-76, 2000. 
[44] T. W. Kernozek, P. A. Wilder, A. Amundson, and J. Hummer, “The effects of body mass index on peak seat-interface pressure of institutionalized elderly," Arch. Phys. Med. Rehabil., vol. 83, pp. 868-871, 2002.

[45] Agency for Health Care Policy and Research, "Pressure ulcer treatment," Clin. Pract Guidel Quick Ref Guide Clin., vol. 15, pp. 1-25, 1994.

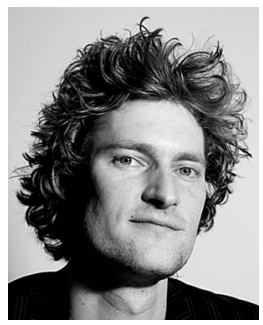

Paul van Geffen was born in 1978 in Waarland, The Netherlands. After receiving his high school degree (VWO diploma) at the GSG in Schagen, he studied Human Kinetic Technology at The Hague University. For his bachelor thesis (B.Sc. 2001), he developed and evaluated a novel ankle-foot orthosis that prevents ankle injury in soccer. Rising interests in rehabilitation and sports medicine took him to the VU University of Amsterdam were he started a master program in human movement science and specialized himself further in biomechanics and exercise physiology. For his master thesis (M.Sc. 2004), he investigated the effects of pacing strategy on the occurrence of fatigue in cycling. On May 14th 2009, he received the Ph.D. degree in the field of biomechanical engineering at the University of Twente, Enschede, The Netherlands, under the supervision of H. F. J. M. Koopman, Ph.D., and P. H. Veltink, Ph.D. His dissertation entitled "Dynamic Sitting" was about the development and evaluation of a dynamic seating system for wheelchair-users with reduced postural stability to control body posture, enhance functional movement and to prevent physical discomfort in prolonged static sitting.

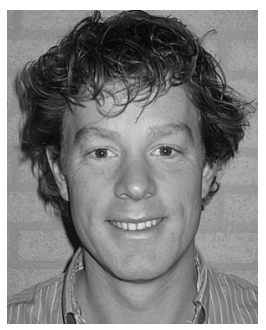

Jasper Reenalda was born in Enschede, The Netherlands, in 1979. After receiving his high school degree he studied human movement science at the Vrije Universiteit, Amsterdam, The Netherlands, where he specialized in sports science and graduated in 2002. In October 2009, he received the Ph.D. degree from the University of Twente, Enschede, The Netherlands, after working on the Dynasit project. In this project, he was involved in the clinical and physiological evaluation of the Dynasit chair.

Besides his work on the Dynasit project, he teaches physiology of sports and exercise at the University of Twente. In addition, he is currently working at Roessingh Research and Development on research projects in the field of rehabilitation science and sport science.

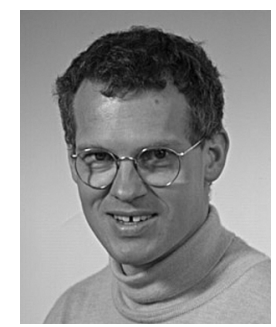

Peter H. Veltink (SM'84) was born in Groenlo, The Netherlands, in 1960. He studied electrical engineering at the University of Twente (M.Sc. cum laude 1984) where he also performed his Ph.D. research in the area of electrical nerve stimulation (Ph.D. 1988).

Currently, he is a Professor of technology for the restoration of human function and Chairman of the Biomedical Signals and Systems Department at the University of Twente, Institute for Biomedical Technology and Technical Medicine (MIRA). His research is in the following areas: biomechatronics, artificial motor control, ambulatory sensing of human motor control (specifically ambulatory movement and force sensing), with applications in rehabilitation medicine and biomechanics; neural engineering: neurostimulation, neuromodulation, DBS, neurocardiology, stimulation of spinal cord and cortex for suppression of pain.

Prof. Veltink is an Associate Editor for the IEEE TRANSACTIONS OF NEURAL SYSTEMS AND REHABILITATION ENGINEERING and reviewer for several scientific journals. He has been the treasurer of the International Functional Electrical Stimulation Society (IFESS) from 1996 to 2001, he is the Chair of the Benelux IEEE-EMBS chapter since 2005. He received the Royal Shell Stimulating Prize for his contribution to the rehabilitation-engineering field in 1997.

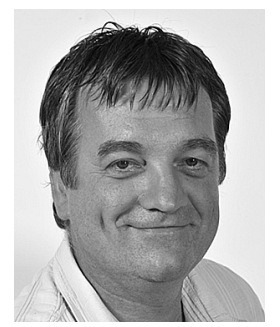

Bart F. J. M. Koopman was born in Oldenzaal, The Netherlands, in 1961. He received the M.Sc. degree in mechanical engineering with specialization fluid dynamics in 1985 and performed his civil service at the Biomechanics Group of the University of Twente. This resulted in a Ph.D. at the end of 1989 on the analysis and prediction of human walking.

When the Laboratory of Biomechanical Engineering was founded in 1990, he started working there as a Faculty Member. He now chairs the Biomechanical Engineering Group. He worked on various topics related to the co-ordination of movement and with applications in rehabilitation, orthopaedics and neurology. The research of the Biomechanical Engineering Group is focussed in three themes: neural mechanics, tissue mechanics and movement mechanics. The most important technological areas that are integrated in the research are control engineering, mechanics of materials, dynamics and design engineering. All research is embedded in the Institute for Biomedical Engineering (Mira) and facilitated by a strong cooperation with various technological and clinical partners. 